\title{
Altered Growth Hormone Secretory Dynamics in Prepubertal Males with Constitutional Delay of Growth
}

\author{
JAMES R. KERRIGAN, PAUL M. MARTHA, JR.,' JOHANNES D. VELDHUIS, \\ ROBERT M. BLIZZARD, AND ALAN D. ROGOL \\ Department of Pediatrics [R.M.B., J.R.K., P.M.M., A.D.R.J, Internal Medicine [J.D.V.], and Pharmacology \\ [A.D.R.], NSF Science and Technology Center for Biological Timing [J.R.K., A.D.R., J.D.V.J, University of \\ Virginia Health Sciences Center, Charlottesville, Virginia 22908
}

\begin{abstract}
We have used the technique of deconvolution analysis to determine if abnormalities in growth hormone (GH) secretion or metabolic clearance underlie the observed alterations in circulating hormone concentrations in a group of seven prepubertal males with constitutional delay of growth (SHORT-DBA). The results were compared with data obtained from 13 healthy, short prepubertal males (SHORT) and 11 healthy prepubertal male subjects of normal stature (NORMAL). Although the mean 12-h overnight $\mathrm{GH}$ production rates were invariant among the groups $(8.0 \pm 1.0$ versus $7.3 \pm 0.7$ versus $6.7 \pm 1.2 \mu \mathrm{g} /$ $\mathrm{L}$, NORMAL versus SHORT versus SHORT-DBA for all comparisons), different secretory mechanisms were operative. The secretory burst half-duration (time interval of the secretory event at half-maximal amplitude) of the SHORT-DBA subjects $(26 \pm 1 \mathrm{~min})$ was greater $(p=$ $0.02)$ than that of the SHORT group $(20 \pm 1 \mathrm{~min})$; values for both the SHORT and SHORT-DBA subjects were indistinguishable from that of NORMAL controls $(22 \pm$ 2 ). Both the mass of GH released per secretory episode and the maximal rate of hormone secretion were less ( $p$ $\leq 0.02$ and $p<0.01$, respectively) for the SHORT-DBA subjects $\left[16 \pm 2 \mu \mathrm{g} / \mathrm{unit}\right.$ of body distribution volume $\left(\mathrm{L}_{v}\right)$ and $0.6 \pm 0.1 \mu \mathrm{g} / \mathrm{L}_{v} / \mathrm{min}$, respectively] compared with those of the NORMAL $\left(26 \pm 2 \mu \mathrm{g} / \mathrm{L}\right.$, and $1.1 \pm 0.1 \mu \mathrm{g} / \mathrm{L}_{\mathrm{v}} / \mathrm{min}$, respectively) and SHORT $\left(28 \pm 4 \mu \mathrm{g} / \mathrm{L}_{\mathrm{v}}\right.$ and $1.3 \pm 0.2 \mu \mathrm{g} /$ $\mathrm{L}_{\mathrm{v}} / \mathrm{min}$, respectively) groups; values for the latter two groups were indistinguishable. Given the dominant association of GH pulse amplitude with normal childhood growth, the present findings suggest a possible GH secretory mechanism underlying the suboptimal growth in a subset of prepubertal males with constitutional delayed growth. (Pediatr Res 33: 278-283, 1993)
\end{abstract}

\section{Abbreviations}

GH, growth hormone

SDS, standard deviation score

SHORT, short, prepubertal male subjects

NORMAL, prepubertal males of normal stature

Received August 18, 1992; accepted November 4, 1992

Correspondence and reprint requests: James R. Kerrigan, M.D., Division of Pediatric Endocrinology, Building MR-4/Room 3037, Box 3, University of Virginia Health Sciences Center, Charlottesville, VA 22908

Supported by Diabetes and Hormone Action Training Grant DK-07320 (J.R.K., P.M.M.), Clinical Investigator Awards HD-00868 (P.M.M.) and HD-00926 (J.R.K.), Research Career Development Award 1-K04-HD-00634 (J.D.V.), NSF Science and Technology Center for Biological Timing (J.R.K. A.D.R., J.D.V.) NIH-supported Clinfo Data Reduction Systems, and a grant from the USPHS (General Clinical Research Centers) to the University of Virginia (RR-00847).

1 Current address: Department of Pediatrics, Baystate Medical Center, 759 Chestnut St., Springfield, MA 01199.
SHORT-DBA, prepubertal male subjects with constitutional delay of growth

BA-SDS, bone age standard deviation score

SRIH, somatotropin release-inhibiting hormone

GHRH, growth hormone-releasing hormone

$\mathrm{L}_{\mathrm{v}}$, body distribution volume

The GH secretory status of children with disordered growth has been the focus of numerous investigations. Many such studies have assessed endogenous $\mathrm{GH}$ levels in children with short stature. Some short children have abnormalities of circulating $\mathrm{GH}$ concentration profiles according to some (1-6) but not other investigators $(7,8)$. The apparent discrepancies between these studies include issues such as the inclusion of different control groups; use of an objective, validated hormone pulse detection program; and the use of different $\mathrm{GH}$ assays. Any or all of these factors, as well as others, may contribute to the differing results.

The mechanism(s) subserving the observed alterations of serum GH concentration profiles in children with subnormal growth are not known. As such, none of the studies described has assessed specific variations in $\mathrm{GH}$ secretion and metabolic clearance. To assess alterations in either secretion or clearance, we have used the technique of deconvolution analysis (9) in a group of children with previously defined abnormalities of endogenous GH concentrations. Deconvolution analysis, or convolution modeling, represents a mathematical technique that, when applied to hormone data series, provides subject-specific estimates of the neurosecretory events and of hormone clearance $(10,11)$. Assuming that $\mathrm{GH}$ secretion occurs in a repetitive, burst-like fashion, convolution modeling characterizes these bursts of pituitary hormone release by their frequency of occurrence, the mass of hormone secreted, the rate of hormone secretion, and the duration of the secretory process. Estimates of hormone production and subject-specific clearance rates can be derived simultaneously from deconvolution analysis. The results of our analysis provide new insight into the altered $\mathrm{GH}$ physiology that characterizes some short prepubertal males with constitutional delay of growth.

\section{SUBJECTS AND METHODS}

Subjects. Thirty-one prepubertal children were enrolled in this study. None had received prior treatment with growth promoting agents. All participants had prepubertal sexual development. None had evidence of systemic disease, intrauterine growth retardation, dysmorphic features, or previous CNS irradiation. Body mass indices (12) were within \pm 2.0 SDS for skeletal age 
for all subjects. The clinical characteristics of all subjects have been reported previously (6).

Thirteen healthy boys with a height SDS of -2.0 or less composed the SHORT group. All had BA within \pm 2.0 SDS based on chronologic age. The SHORT-DBA group was composed of seven healthy male subjects with a height SDS of -2.0 or less and bone age SDS of -2.0 or less for chronologic age. Subjects in both the SHORT and SHORT-DBA groups had GH concentrations of $>10 \mu \mathrm{g} / \mathrm{L}$ after pharmacologic testing. Eleven healthy males composed the NORMAL group. All had height SDS, weight SDS, and BA SDS within \pm 2.0 for chronologic age.

Auxologic measurements were normalized according to the data of Tanner and Davies (13). Pubertal staging was based on genital development according to the method of Marshall and Tanner (14). Skeletal maturation and SDS were determined according to the method of Tanner et al. (15).

Protocol. The study was approved by the Human Investigation Committee at the University of Virginia and was performed in at institution's General Clinical Research Center. Participants were informed of the details of the investigation. Legal consent and assent were then provided by the parents or legal guardians and the children, respectively.

An i.v. catheter with heparin lock was inserted into a forearm vein at least $2 \mathrm{~h}$ before sampling. Venous blood samples were obtained every $20 \mathrm{~min}$ via the indwelling catheter beginning at $2000 \mathrm{~h}$ and continuing through $0800 \mathrm{~h}$. Subjects were allowed normal activity and were provided caffeine-free meals and snacks.

Assays. Serum GH concentrations were determined in duplicate by an immunoradiometric assay (Nichols Institute, San Juan Capistrano, CA) using the supplied horse-serum matrix. The limit of assay detection is $0.5 \mu \mathrm{g} / \mathrm{L}$ with intra- and interassay coefficients of variation of $\leq 8.0$ and $\leq 10.0 \%$, respectively. All samples obtained from a given subject were measured in a single assay run to avoid interassay variability. Plasma IGF-I concentrations were determined using a double-antibody RIA kit (Nichols Institute).

Deconvolution analysis. Based on the premise that $\mathrm{GH}$ and other anterior pituitary hormones are secreted in a burst-like fashion and that hormone elimination occurs at subject-specific metabolic clearance rates (9), we used deconvolution analysis to estimate the following dynamic measures of GH secretion and removal: 1) number and positions in time of the secretory episodes, 2) secretory burst half-duration (duration of the secretory episode at half-maximal amplitude), 3) amplitude (maximal secretory rate in each secretory burst, and 4) GH half-life corresponding to a disappearance rate constant. Multiple-parameter deconvolution analysis assumes that the simultaneous operation of these four sets of parameters gives rise to the circulating $\mathrm{GH}$ concentrations (9). The mass of GH secreted per episode was calculated as the integral (area) of the deconvolution-resolved secretory burst. The 12 -h GH production rate was calculated as the product of the average mass of hormone secreted per burst and the total number of secretory bursts. An assumption of multiple-parameter deconvolution analysis is that each secretory burst can be approximated statistically by a gaussian distribution of release rates. No constitutive secretion was necessary to model the present experimental data.

Statistical analyses. Group values were compared using oneway analysis of variance with Duncan's multiple-range test. Secretory parameters were log-transformed because they are not normally distributed (10). Univariate linear regression analysis was used to assess correlations. Statistical significance was accepted at a $p$ value of $<0.05$. Results are reported as mean \pm SEM.

\section{RESULTS}

The clinical characteristics of all the study groups are displayed in Table 1. The average chronologic and skeletal ages were
Table 1. Clinical characteristics of study participants*

\begin{tabular}{lccc}
\hline & NORMAL & SHORT & SHORT-DBA \\
\hline CA (y) & $9.0 \pm 0.3$ & $9.5 \pm 0.5$ & $10.4 \pm 1.0$ \\
BA (y) & $8.2 \pm 0.4$ & $9.1 \pm 0.6$ & $7.6 \pm 0.8$ \\
BA SDS & $-0.8 \pm 0.8^{\mathrm{a}}$ & $-0.4 \pm 0.2^{\mathrm{a}}$ & $-2.6 \pm 0.2^{\mathrm{b}}$ \\
Height SDS & $0.1 \pm 0.3^{\mathrm{a}}$ & $-2.6 \pm 0.2^{\mathrm{b}}$ & $-3.1 \pm 0.2^{\mathrm{b}}$ \\
GV SDS & $1.0 \pm 0.7^{\mathrm{a}}$ & $-1.2 \pm 0.4^{\mathrm{b}}$ & $-1.8 \pm 0.6^{\mathrm{b}}$ \\
\hline
\end{tabular}

$*$ Values (mean \pm SEM) within a row without identical superscripts differ statistically $(p \leq 0.03)$. CA, chronologic age; BA, bone age; $\mathrm{GV}$, growth velocity.

indistinguishable among the groups. Skeletal age, expressed as SDS, was significantly $(p<0.001)$ less (by experimental design) for the SHORT-DBA group compared with those of both other groups. Values for height SDS and growth velocity SDS for both the SHORT and SHORT-DBA groups were significantly $(p<$ 0.001 and $p<0.01$, respectively) less than those of the NORMAL subjects but indistinguishable from each other.

Typical profiles obtained by deconvolution analysis are shown in Figure 1; a representative reconvolved serum GH concentration versus time graph and a $\mathrm{GH}$ secretory rate versus time curve are illustrated for each group. The numerical results of deconvolution analysis for the three study groups are listed in Table 2.

The secretory burst half-duration (time interval of the secretory event at half-maximal amplitude) of the SHORT-DBA subjects $(26 \pm 1 \mathrm{~min})$ was greater $(p=0.02)$ than that of the SHORT group ( $20 \pm 1 \mathrm{~min}$ ); values for both the SHORT and SHORTDBA subjects were indistinguishable from those of the NORMAL controls $(22 \pm 2)$. Both the mass of $\mathrm{GH}$ released per secretory episode and the maximal rate of hormone secretion were less ( $p \leq 0.02$ and $p<0.01$, respectively) for the SHORTDBA subjects $\left(16 \pm 2 \mu \mathrm{g} / \mathrm{L}_{\mathrm{v}}\right.$ and $0.6 \pm 0.1 \mu \mathrm{g} / \mathrm{L}_{\mathrm{v}} / \mathrm{min}$, respectively) compared with those of the NORMAL $\left(26 \pm 2 \mu \mathrm{g} / \mathrm{L}_{\mathrm{v}}\right.$ and $1.1 \pm 0.1 \mu \mathrm{g} / \mathrm{L}_{\mathrm{v}}$, respectively) and SHORT $\left(28 \pm 4 \mu \mathrm{g} / \mathrm{L}_{\mathrm{v}}\right.$ and $1.3 \pm 0.2 \mu \mathrm{g} / \mathrm{L}_{\mathrm{v}} / \mathrm{min}$, respectively) groups; values for the last two groups were indistinguishable. The mean 12-h serum GH concentrations, secretory burst frequencies, and $12-\mathrm{h} \mathrm{GH}$ production rates [expressed as mass of $\mathrm{GH}$ per unit of body distribution volume $\left(\mathrm{L}_{v}\right)$, mass of $\mathrm{GH}$ per unit of body surface area, or mass of $\mathrm{GH} / \mathrm{kg}$ of body mass] were indistinguishable among the study groups. Comparisons of secretory burst frequency, mass of $\mathrm{GH}$ released per secretory burst, maximal rate of hormone secretion, and $\mathrm{GH}$ production rate are depicted in Figure 2. Endogenous GH half-life estimates were indistinguishable among the study groups; the derived estimates are in general agreement with independently obtained values in adults and children (16-20).

Shown in Table 3 are the results of linear-regression analysis for several GH secretion characteristics and BA SDS for all subjects combined. Significant correlations were observed between secretory burst half-duration $(r=-0.41, p=0.02)$, the mass of $\mathrm{GH}$ released per secretory episode $(r=0.43, p=0.02)$, and maximal rate of $\mathrm{GH}$ secretion attained within a burst (amplitude) $(r=0.46, p=0.01)$ versus BA SDS. The relationships between BA SDS and the mass of GH released per secretory burst and the rate of GH secretion are illustrated in Figure 3. No significant relationship was observed between $\mathrm{GH}$ production rate $(r=0.24, p=0.20)$ and $\mathrm{BA} \operatorname{SDS}$.

\section{DISCUSSION}

Subnormal concentrations of GH released spontaneously over 12 to $24 \mathrm{~h}$ have been observed in some children with short stature (1-6). In particular, diminished GH pulse amplitudes occur in some healthy, short children. The significance of this finding is suggested by the data of Hindmarsh et al. (21) who observed a positive curvilinear relationship between the amplitude of circulating GH pulses and linear growth velocity. Most recently, these same investigators have obtained data that support the concept that the rate of change of endogenous $\mathrm{GH}$ concentrations 
NORMAL
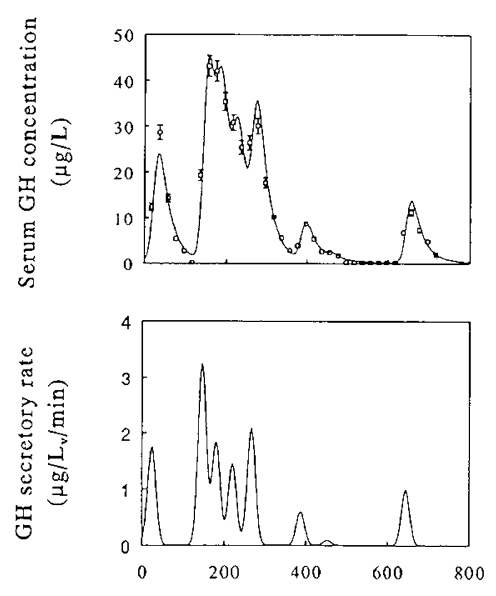

SHORT
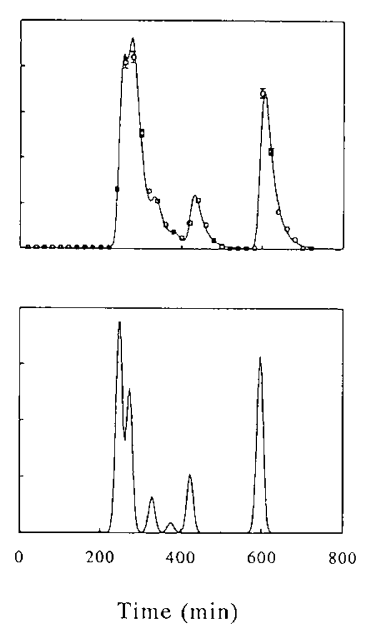

SHORT-DBA
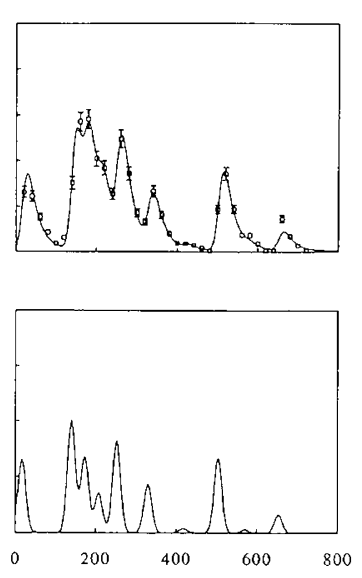

Fig. 1. Shown in this composite figure are data from a representative subject in each of the three study groups: one control (the two graphs on the left), one short boy with normal skeletal development (the two graphs in the center), and a child with short stature and delayed bone age (the two graphs on the right). The vertical axes for the three graphs in each row have identical ranges of values. The upper panels depict the deconvolutionpredicted curves and the measured serum GH concentrations (shown as open boxes with vertical error bars representing the intrasample SD); the deconvolution-derived curves closely approximate the experimental data points. The bottom panels illustrate the distinct GH secretory bursts as estimated by deconvolution analysis and are represented as secretory rate $v s$ time.

Table 2. Characteristics of $G H$ secretion, $G H$ half-life, and plasma IGF-I levels*

\begin{tabular}{|c|c|c|c|}
\hline & NORMAL & SHORT & SHORT-DBA \\
\hline $\begin{array}{l}\text { Mean } 12 \text { h serum } \mathrm{GH} \\
\text { concentration }(\mu \mathrm{g} / \mathrm{L})\end{array}$ & $8.0 \pm 1.0$ & $7.3 \pm 0.7$ & $6.7 \pm 1.2^{\mathrm{NS}}$ \\
\hline $\begin{array}{l}\text { Secretory burst half- } \\
\text { duration (min) }\end{array}$ & $22 \pm 2^{a . b}$ & $20 \pm 1^{a}$ & $26 \pm 1^{b}$ \\
\hline $\begin{array}{l}\text { No. of secretory bursts/ } \\
12 \mathrm{~h}\end{array}$ & $8.2 \pm 0.6$ & $8.8 \pm 0.7$ & $11.0 \pm 1.4^{\mathrm{NS}}$ \\
\hline $\begin{array}{l}\text { Mass of GH released per } \\
\text { burst }\left(\mu \mathrm{g} / \mathrm{L}_{\mathrm{v}}\right)\end{array}$ & $26 \pm 2^{a}$ & $28 \pm 4^{a}$ & $16 \pm 2^{b}$ \\
\hline $\begin{array}{l}\text { Maximal rate of } \mathrm{GH} \\
\text { secretion per burst } \\
\left(\mu \mathrm{g} / \mathrm{L}_{v} / \mathrm{min}\right)\end{array}$ & $1.1 \pm 0.1^{\mathrm{a}}$ & $1.3 \pm 0.2^{\mathrm{a}}$ & $0.6 \pm 0.1^{b}$ \\
\hline $\begin{array}{l}\text { GH production rate } \\
\left(\mu \mathrm{g} / \mathrm{L}_{\mathrm{v}} \times 12 \mathrm{~h}\right)\end{array}$ & $214 \pm 26$ & $225 \pm 24$ & $178 \pm 29^{\mathrm{NS}}$ \\
\hline $\begin{array}{l}\text { GH production rate } \\
\left(\mu \mathrm{g} / \mathrm{m}^{2} \times 12 \mathrm{~h}\right)\end{array}$ & $476 \pm 57$ & $461 \pm 47$ & $366 \pm 57^{\mathrm{NS}}$ \\
\hline $\begin{array}{l}\text { GH production rate } \\
(\mu \mathrm{g} / \mathrm{kg} \times 12 \mathrm{~h})\end{array}$ & $17 \pm 2$ & $18 \pm 2$ & $14 \pm 2$ \\
\hline Half-life (min) & $22 \pm 2$ & $20 \pm 2$ & $26 \pm 1$ \\
\hline IGF-I $(\mathrm{IU} / \mathrm{mL}) \dagger$ & $\begin{array}{l}0.90 \pm 0.13 \\
(0.34-1.77)\end{array}$ & $\begin{array}{l}0.60 \pm 0.06^{\mathrm{a}} \\
(0.22-1.10)\end{array}$ & $\begin{array}{l}0.65 \pm 0.12^{\mathrm{a}} \\
(0.22-1.18)\end{array}$ \\
\hline
\end{tabular}

* Values (mean \pm SEM) within a row without identical superscripts differ statistically $(p<0.04)$. Superscript NS denotes no significant difference.

$\dagger$ Values in parentheses represent the range of IGF-I concentrations.

is an important signal for the control of growth (22). As such, these findings underscore the important role of the pulsatile pattern of GH secretion in the modulation of normal childhood growth. However, the precise role and characteristics of pituitary $\mathrm{GH}$ secretion and metabolic clearance of the $\mathrm{GH}$ molecule in the modulation of growth in otherwise healthy short children has not been fully addressed.

We have therefore applied deconvolution analysis to determine if alterations in pituitary GH secretion and the consequent hormone production rate or in hormone clearance exist in a group of healthy, short, prepubertal males. Multiple-parameter deconvolution analysis is a computerized mathematical technique that, when applied to deconvolutional hormone concentration versus time series, provides subject-specific estimates of hormone secretion and elimination characteristics. Thus, the application of this mathematical technique provides mechanistic insight into the kinetics of the secretory events and the metabolic clearance of the GH molecule.

In the present study, average circulating levels of $\mathrm{GH}$ did not differ among the groups. Different mechanisms of hormone secretion, however, were existent. In the short subjects with delayed skeletal maturation, the average duration of $\mathrm{GH}$ secretory episodes was prolonged compared with the other short subjects. This abnormality has also been observed recently in young girls with Turner's syndrome (23). A diminished mass of $\mathrm{GH}$ released per secretory episode and a decreased average maximal rate of hormone secretion were observed in the same subjects. Although a trend toward decreased $12-\mathrm{h}$ GH production rates was observed for the SHORT-DBA group, the results did not achieve statistical significance. The prolonged duration of secretion and trends toward a greater secretory burst frequency and a lengthened hormone half-life, both of which have been recognized in prepubertally aged girls with Turner's syndrome (above), would contribute to increased circulating GH concentrations. The decreased mass of hormone released per burst and diminished rate of $\mathrm{GH}$ release, however, would result in lowered $\mathrm{GH}$ levels. The net result of these simultaneously acting mechanisms is an invariant average concentration of spontaneously circulating $\mathrm{GH}$ and unaltered $\mathrm{GH}$ production rates.

The findings of the present study provide some insight into the pathophysiology of altered $\mathrm{GH}$ secretion and suboptimal growth in a subset of healthy, prepubertal males with constitutional delayed growth. The pulsatile pattern of $\mathrm{GH}$ secretion arises from episodic increases and decreases in the release and subsequent action of GHRH and SRIH on the somatotrope (24, 25 ). In the simplest interpretation of available data, the amount of GHRH released determines the amount of $\mathrm{GH}$ released per secretory episode and the pattern of SRIH action determines the frequency and duration of the GH secretory bursts (26-28).

The findings of the present study support the concept that a relative deficiency of the amount of GHRH released per burst (but not the indirectly inferred frequency of GHRH bursts) plays an important role in the altered $\mathrm{GH}$ secretion observed in prepubertal males with constitutional delay of growth. In support of this concept are the diminished mass of $\mathrm{GH}$ released per burst and a decreased maximal rate of hormone release. Although these findings might also be explained by heightened SRIH tone, 


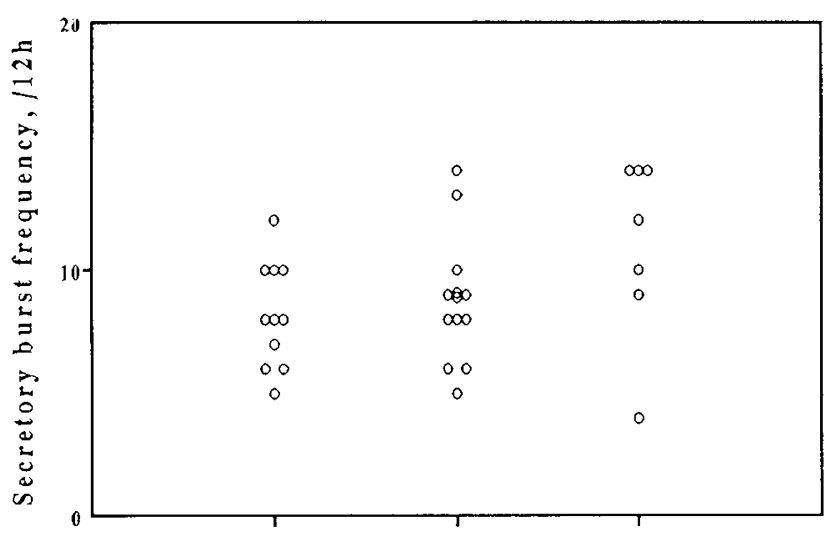

Normal Short Short-DBA

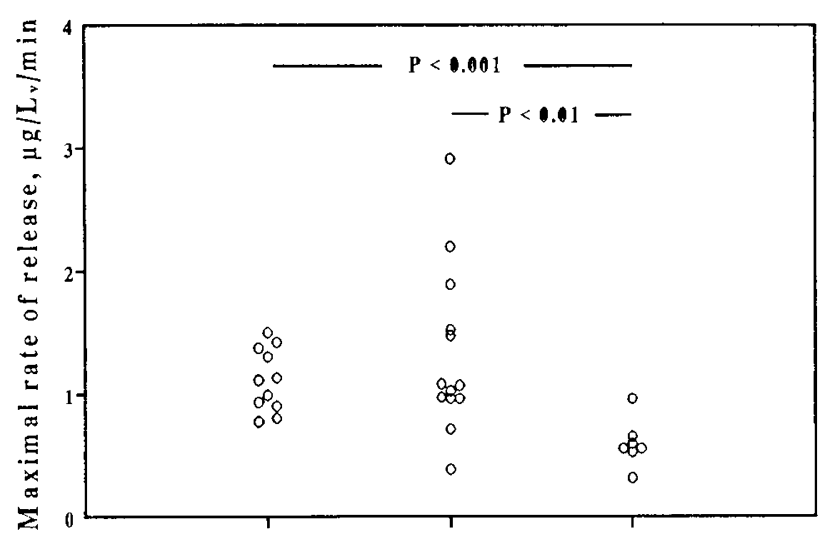

Normal Short Short-DBA
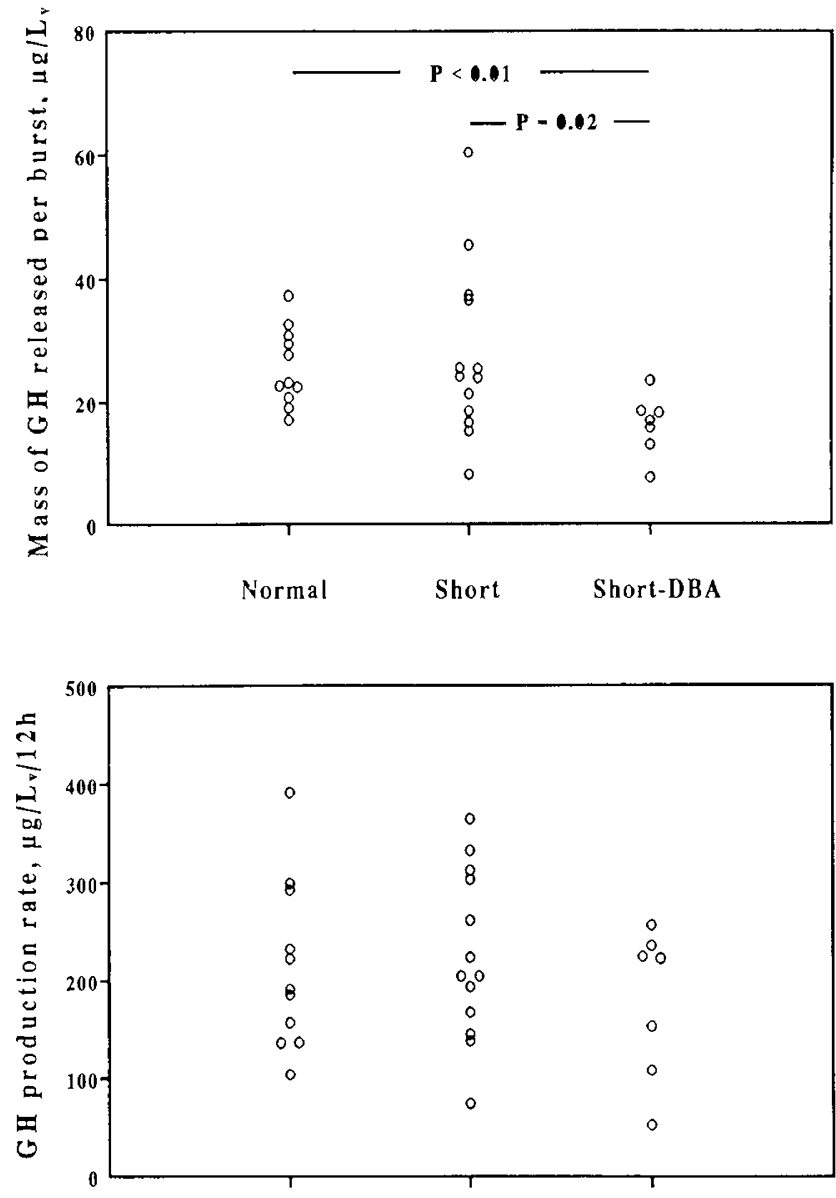

Normal Short Short-DBA

Fig. 2. Illustrated in this composite figure are comparisons (among the three study groups) of GH secretory burst frequency (top left panel), mass of GH released per burst (lop right panel), amplitude or maximal rate of GH secretion attained within bursts (bottom left panel), and 12-h GH production rate (bottom right panel). Statistically different group values are denoted by connecting lines with the respective $p$ values.

Table 3. Correlation analysis of selected GH secretory burst characteristics and BA SDS of all study subjects

\begin{tabular}{lcc}
\multicolumn{3}{c}{ characteristics and BA SDS of all study subjects } \\
\hline & $\begin{array}{c}\text { Correlation } \\
\text { coefficient }\end{array}$ & $p$ value \\
\hline Secretory burst half-duration $(\mathrm{min})$ & -0.41 & 0.02 \\
Mass of $\mathrm{GH}$ released per secretory epi- & 0.43 & 0.02 \\
$\quad$ sode $\left(\mu \mathrm{g} / \mathrm{L}_{\mathrm{v}}\right)$ & & \\
Rate of $\mathrm{GH}$ secretion $\left(\mu \mathrm{g} / \mathrm{L}_{\mathrm{v}} / \mathrm{min}\right)$ & 0.46 & 0.01 \\
GH production rate $\left(\mu \mathrm{g} / \mathrm{L}_{\mathrm{v}} / 12 \mathrm{~h}\right)$ & 0.24 & 0.20 \\
\hline
\end{tabular}

additional evidence in support of altered GHRH action is derived from presumptive inhibition of SRIH secretion by $\beta$-adrenergic blockade. Spontaneous release of $\mathrm{GH}$ fails to rise after administration of atenolol, a $\beta$-adrenergic blocking agent, to healthy, prepubertal males with constitutional delay of growth (29). These data suggest that perturbed GHRH action, rather than disturbance of SRIH effect, plays a critical role in the altered GH secretion in prepubertal males with constitutional delayed growth. The increased secretory burst duration, however, may not be due entirely to altered GHRH action. There are likely direct GHRH-SRIH interactions within the hypothalamus (30). The consequence of a disruption of these normal interactions may be manifested as altered rate and/or duration of hormone secretion and, conceivably, altered frequency of GH secretory episodes. Of interest, an increased frequency of low-amplitude GH secretory bursts has been described recently as a statistically positive predictor of clinical linear-growth responses to $\mathrm{GH}$ administration in Turner's syndrome (31).
The sex-steroid hormones are known to significantly alter $\mathrm{GH}$ secretion $(32,33)$. By definition, subjects with constitutional delayed growth and adolescence have a prolonged period of relative sex-steroid hormone insufficiency. One may speculate that the apparent (and relative) deficiency of GHRH in our subjects with constitutional delay is the result of this suboptimal action of gonadal steroid hormones in the prepubertal period. In support of such a relationship is the ability of very small doses of estrogen to increase $\mathrm{GH}$ secretion 2- to 3-fold in prepubertal girls with Turner's syndrome (34). Administration of androgen to young males with constitutional delay of growth and adolescence results in augmented GH secretion (35). Specifically, both the mass and maximal rate of $\mathrm{GH}$ released per secretory episode were increased in these subjects. Saggese et al. (36) have recently reported decreased circulating concentrations of GHRH in prepubertal subjects with constitutional delayed development. No such abnormality was observed in these subjects during adolescent development, a time of augmented sex-steroid hormone levels. No alterations in peripheral SRIH concentrations were observed. Although of interest, the precise relevance of such measurements to changes in the levels of GHRH and SRIH in hypophyseal portal blood remains to be tested.

Recently, Veldhuis et al. (37) used deconvolution analysis to quantitate pituitary $\mathrm{GH}$ secretion and circulating $\mathrm{GH}$ half-life in a group of healthy, prepubertal males with idiopathic short stature. No differences were noted, however, for any characteristics of hormone secretion or of the estimated, subject-specific half-lives. Although no apparent mathematical relationship was observed between various specific quantitative parameters of $\mathrm{GH}$ 

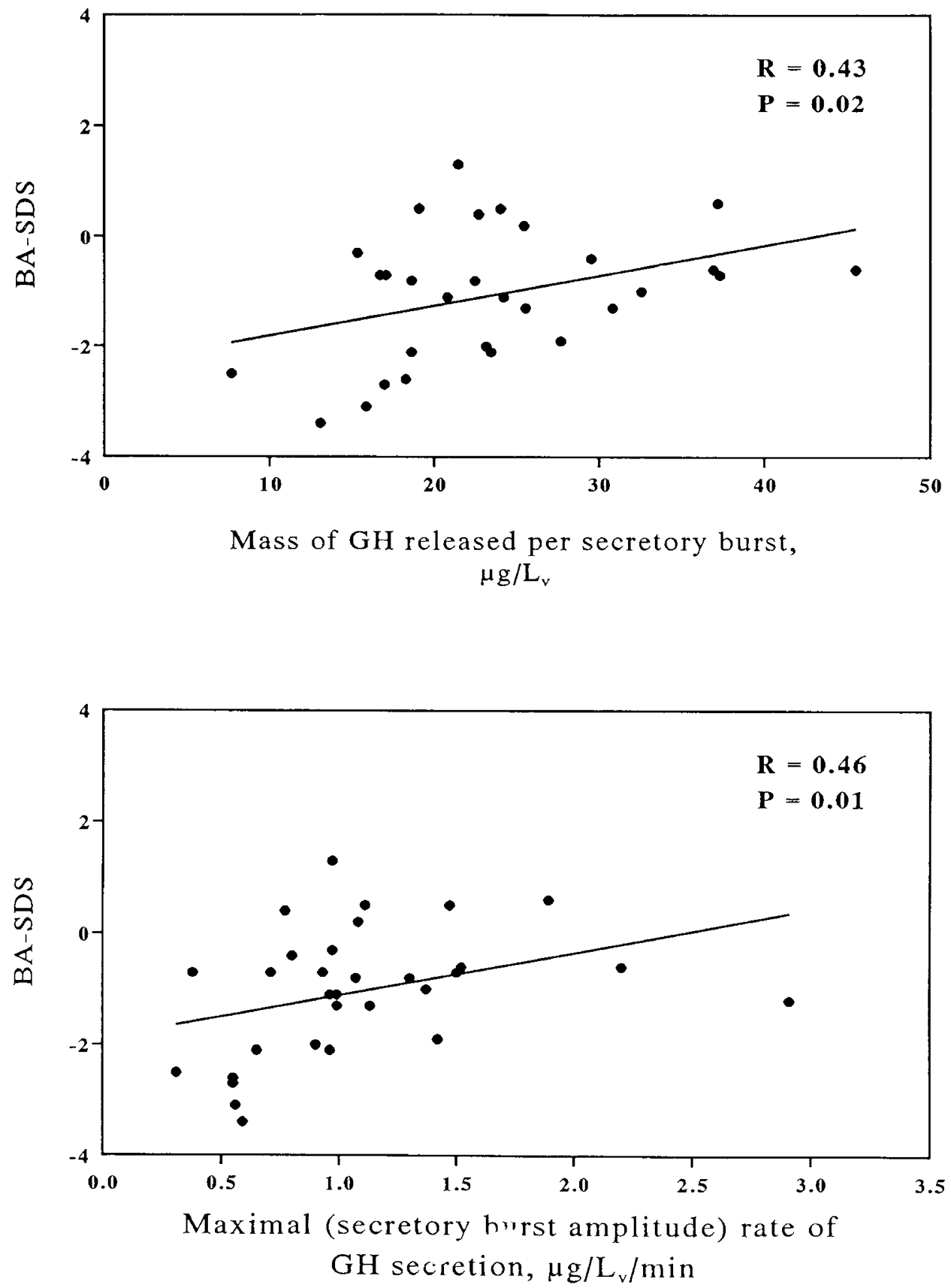

Fig. 3. Relationships (as determined by univariate linear regression analysis) between skeletal maturation (expressed as BA SDS) and the mass of GH released per secretory burst (top panel) and the rate of GH secretion (bottom panel) are illustrated. The respective correlation coefficients and $p$ values are displayed in the upper right corner of each graph.

secretion and skeletal age, those subjects with significantly delayed bone ages were not evaluated separately and constituted a small percentage of the group. Thus, inferences concerning the mode of GH secretion in subjects with constitutional delayed growth and development in that study are not possible.

In summary, 12-h overnight GH production rates for healthy, short, prepubertal males did not differ from values for control subjects of normal stature. In a subset of short boys with constitutional delay of growth (i.e. those short boys with significantly delayed bone age), however, several characteristics of GH secretion were altered; among these were decreased mass of hormone released per secretory burst, prolonged GH secretion episodes, and diminished maximal rate of $\mathrm{GH}$ secretion attained within each burst. The frequency of $\mathrm{GH}$ secretory burst and the endogenous GH half-life were invariant. The observed alterations in GH secretory dynamics may underlie the suboptimal growth in some prepubertal males with constitutional delay of growth and provide insight into the neuroendocrine mechanisms subserving such altered GH physiology.

Acknowledgments. The authors thank Sandra Jackson, Margaret Wood Ball, and the nursing staff at The General Clinical Research Center for their expert care of research subjects and Ginger Bauler, Catherine Kern, and David Carter for technical assistance. We gratefully acknowledge the superb clerical assistance of Susan Lorek Fitzgerald.

\section{REFERENCES}

l. Bierich JR 1983 Treatment of constitutional delay of growth and adolescence with human growth hormone. Klin Padiatr 195:309-316

2. Spiliotis BE, August GP, Hung W, Sonis W, Mendelson W, Bercu BB 1984 Growth hormone neurosecretory dysfunction: a treatable cause of short stature. JAMA 251:2223-2230 
3. Zadik Z, Chalew SA, Raiti S, Kowarski AA 1985 Do short children secrete insufficient growth hormone? Pediatrics 76:355-360

4. Sanayama K, Noda H, Konda S, Ikeda F, Murata A, Sasaki N, Niimi H, Nakajima H 1987 Spontaneous growth hormone secretion and plasma somatomedin-C in children of short stature. Endocrinol Jpn 34:627-633

5. Ghizzoni L, Lamborghini A, Ziveri M, Volta C, Panza C, Balestrazzi P, Bernasconi S 1990 Pulsatile growth hormone release in Turner's syndrome and short normal children. Acta Endocrinol (Copenh) 123:291-297

6. Kerrigan JR, Martha Jr PM, Blizzard RM, Christie CM, Rogol AD 1990 Variations of pulsatile growth hormone release in healthy short prepubertal boys. Pediatr Res 28:11-14

7. Lanes R, Bohorquez L, Leal V, Hernandez G, Borges M, Hurtado E, Moncada G 1986 Growth hormone secretion in patients with constitutional delay of growth and pubertal development. J Pediatr 109:781-783

8. Lin TH, Kirkland RT, Sherman BM, Kirkland JL 1989 Growth hormone testing in short children and their response to growth hormone therapy. $J$ Pediatr 115:57-63

9. Veldhuis JD, Carlson ML, Johnson ML 1987 The pituitary gland secretes in bursts: appraising the nature of glandular secretory impulses by simultaneous multiple-parameter deconvolution of plasma hormone concentrations. Proc Natl Acad Sci USA 84:7686-7690

10. Veldhuis JD, Faria A, Vance ML, Evans WS, Thorner MO, Johnson ML 1988 Contemporary tools for the analysis of episodic growth hormone secretion and clearance in vivo. Acta Paediatr Scand 347:63-82

11. Veldhuis JD, Johnson ML 1992 Deconvolution analysis of hormone data Methods Enzymol 210:539-575

12. Hammer LD, Kraemer HC, Wilson DM, Ritter PL, Dornbusch SM 1991 Standardized percentile curves of body-mass index for children and adolescents.Am J Dis Child 145:259-263

13. Tanner JM, Davies PSW 1985 Clinical longitudinal standards for height and height velocity for North American children. J Pediatr 107:317-329

14. Marshall WA, Tanner JM 1970 Variation in the pattern of pubertal changes in boys. Arch Dis Child 45:13-23

15. Tanner JM, Whitehouse RH, Cameron N, Marshall WA, Healy MJR, Goldstein H 1983 Assessment of skeletal maturation and prediction of adult height (TW2 Method). Academic Press, New York

16. Parker ML, Utiger RD, Daughaday WH 1962 Studies on human growth hormone. Il. The physiological disposition and metabolic fate of human growth hormone in man. J Clin Invest 41:262-267

17. Kowarski A, Thompson RG, Migeon CJ, Blizzard RM 1971 Determination of integrated plasma concentrations and true secretion rates of human growth hormone. J Clin Endocrinol Metab 32:356-360

18. Albertsson-Wikland K, Rosberg S, Libre E, Lundberg LO, Growth T 1989 Growth hormone secretory rates in children as estimated by deconvolution analysis of 24-h plasma concentration profiles. Am J Physiol 257:E809E814

19. Faria ACS, Veldhuis JD, Thorner MO, Vance ML 1989 Half-time of endogenous growth hormone disappearance in normal man after stimulation of $\mathrm{GH}$ secretion by GHRH and suppression with somatostatin. J Clin Endocrinol Metab 68:535-541

20. Rosenbaum M, Gertner JM 1989 Metabolic clearance rates of synthetic human growth hormone in children, adult women, and adult men. J Clin Endocrinol Metab 69:821-824

21. Hindmarsh P, Smith PJ, Brook CGD, Matthews DR 1987 The relationship between height velocity and growth hormone secretion in short prepubertal children. Clin Endocrinol 27:581-591

22. Hindmarsh PC, Matthews DR, Stratton I, Pringle PJ, Brook CGD 1992 Rate of change (modulation) of serum growth hormone concentrations is a more important factor in determining growth rate than duration of exposure. Clin Endocrinol 36:165-170

23. Veldhuis JD, Sotos JF, Sherman BM, Genentech Collaborative Group 1991 Decreased metabolic clearance of endogenous growth hormone and specific alterations in the pulsatile mode of growth hormone secretion occur in prepubertal girls with Turner's syndrome. J Clin Endocrinol Metab 73:10731080

24. Tannenbaum GS, Ling N 1984 The interrelationship of growth hormone (GH)-releasing factor and somatostatin in generation of the ultradian rhythm of GH secretion. Endocrinology 115:1952-1957

25. Plotsky PM, Vale W 1985 Patterns of growth hormone-releasing factor and somatostatin secretion into the hypophyseal portal circulation in the rat. Science 230:461-463

26. Kraicer J, Sheppard MS, Luke J, Lussier B, Moor BC, Cowan JS 1988 Effect of withdrawal of somatostatin and growth hormone $(\mathrm{GH})$-releasing factor on GH release in vitro. Endocrinology 122:1810-1815

26. Weiss J, Cronin MJ, Thorner MO 1987 Periodic interactions of GH-releasing factor and somatostatin can augment $\mathrm{GH}$ release in vitro. Am $\mathrm{J}$ Physiol 253:E508-E514

28. Stachura ME, Tyler JM, Farmer PK 1988 Combined effect of human growth hormone (GH)-releasing factor-44 (GRF) and somatostatin (SRIF) on postSRIF rebound release of GH and prolactin: a model for GRF-SRIF modulation of secretion. Endocrinology 123:1476-1482

29. Martha Jr PM, Blizzard RM, Rogol AD 1988 Atenolol enhances growth hormone release to exogenous growth hormone-releasing hormone but fails to alter spontaneous nocturnal growth hormone secretion in boys with constitutional delay of growth. Pediatr Res 23:393-397

30. Frohman LA, Jansson J-O 1986 Growth hormone-releasing hormones. Endocrinol Rev 7:223-253

31. Kamp GA, Kuilboer MM, Winne HJ, Rongen-Westerlaken C, Johnson ML, Veldhuis JD, Wit JM 1993 Slow baseline growth and a good response to $\mathrm{GH}$ therapy are related to elevated spontaneous $\mathrm{GH}$ pulse frequency in girls with Turner's syndrome. J Clin Endocrinol Metab (in press)

32. Kerrigan JR, Rogol AD 1992 The impact of gonadal steroid hormone action on growth hormone secretion during childhood and adolescence. Endocrinol Rev 13:281-298

33. Martha Jr PM, Gorman KM, Blizzard RM, Rogol AD, Veldhuis JD 1992 Endogenous growth hormone secretion and clearance rates in normal boys as determined by deconvolution analysis: relationship to age, pubertal status and body mass. J Clin Endocrinol Metab 74:336-344

34. Mauras N, Rogol AD, Veldhuis JD 1990 Increased hGH production rate after low-dose estrogen therapy in prepubertal giris with Turner's syndrome. Pediatr Res 28:626-630

35. Ulloa-Aguirre A, Blizzard RM, Garcia-Rubi E, Rogol AD, Link K, Christi CM, Johnson ML, Veldhuis JD 1990 Testosterone and oxandrolone, a nonaromatizable androgen, specifically amplify the mass and rate of growth hormone $(\mathrm{GH})$ secreted per burst without altering $\mathrm{GH}$ secretion burst duration or frequency or the GH half-life. J Clin Endocrinol Metab 71:846854

36. Saggese G, Cesaretti G, Giannessi N, Bracaloni C, Cinquanta L, Cioni C 1992 Stimulated growth hormone $(\mathrm{GH})$ secretion in children with delays in pubertal development before and after the onset of puberty: relationship with peripheral plasma $\mathrm{GH}$-releasing hormone and somatostatin levels. J Clin Endocrinol Metab 74:272-278

37. Veldhuis JD, Blizzard RM, Rogol AD, Martha Jr PM, Kirkland JL, Sherman BM, Genentech Collaborative Group 1992 Properties of spontaneous growth hormone secretory bursts and half-life of endogenous growth hormone in boys with idiopathic short stature. J Clin Endocrinol Metab 74:766-773 